\title{
South African Sign Language - one language or many?
}

A sociolinguistic question

\author{
Debra Aarons, University of Stellenbosch \\ Philemon Akach, Deaf Federation of South Africa
}

\section{Introduction}

In this article we discuss the signed language used by the Deaf community in South Africa, and examine the historical conditions for its emergence. We describe the legal and actual situation of South African Sign Language in South Africa today, particularly in relation to schooling. We investigate the different factors that underlie the claims that there is more than one sign language in South Africa, and we spell out the practical consequences of accepting these claims without further examination.

We assume without argument that Deaf' people in South Africa, far from being deficient, or disabled, are a linguistic minority, with their own language, South African Sign Language, and their own culture, South African Deaf culture ${ }^{2}$. Like everyone else in this post-modernist world, Deaf people have differential membership in many different cultures, on the basis of, for instance, religion, life-style, daily practices, political beliefs, and education. However, what they all have in common is membership in a community that uses signed language, and that socialises with other people who do the same ${ }^{3}$.

Thus, the model we adopt is non-medical. We are not interested here in degree of hearing loss, the remediation of hearing, audiological measures, speech therapy, or any other medical views of deafness. We regard deafness only as the sufficient, but

\footnotetext{
${ }^{1}$ In accordance with convention in the field of Deaf Studies, we use upper case $D$ (Deaf) when we refer to people who identify with the Deaf community and who use signed language, and lower case $d$ (deaf) to refer merely to the audiological condition.

${ }^{2}$ See, for further argurnent and discussion, Aarons 1996.

${ }^{3}$ For an interesting and full discussion of e.g., American Deaf Culture, see Padden and Humphries, Voices from a Culture 1990.
} 
not necessary precipitant of signed language development, and our concern here is to examine certain sociolinguistic issues that come into play in the consideration of the status of the signed language used in South Africa.

\section{The status of natural signed languages internationally}

It is by now uncontroversial, at least among linguists, that natural signed languages used by the Deaf in different parts of the world, are fully-fledged languages, equivalent in all respects to all other natural languages that have been studied. They are acquired naturally by young children, at the same rate, and with the same ease that spoken languages are acquired. They are functionally capable of expressing the entire range of human experience that spoken languages are able to express; they have as many registers, and as much complexity as any other human language. Signed languages have phonological, morphological, syntactic, and semantic levels of representation. These have been shown to be exactly the same as those proposed for any other human language. The distinguishing feature of signed languages is that they are made through the medium of space, not sound, and that they use the hands, face, head and upper torso for their realisation.

There is no one universal signed language. Signed languages, just like other languages, arise naturally, through use by a community of users in a context of natural use, and they evolve and develop over time as they are passed down from generation to generation. They differ from most spoken languages in the important respect that only $10 \%$ of deaf children are bom to deaf parents, and thus, Deaf children tend to learn signed language from other Deaf children and adults, and not usually from birth, in their own homes. This, added to the fact that signed languages are not written down, probably leads to a slightly higher degree of variability in the signed language of a community. However, in general, the signed language used in one country is identifiably distinct from the signed language used in another country, particularly where these countries are geographically and historically unrelated. Thus, for instance, Namibian Sign Language and Thai Sign Language are mutually unintelligible. 
Furthermore, signed languages are not related to the spoken language of the geographical area in which they occur. Although English is the primary spoken language in Britain and the USA, the signed languages of these two countries are not related. If we compare American Sign Language and British Sign Language, we see that these two languages are mutually unintelligible. Historically, American Sign Language is related to Old French Sign Language, since the first teachers of the Deaf in the USA came from France. In any event, the indigenous signed language in the USA did not evolve from the indigenous signed language in Britain. South African Sign Language (as the case in point) can trace some of its influences to Irish Sign Language, but less so to British Sign Language.

In certain countries of the world, the natural signed language used by the Deaf is accorded official status. The signed language used by the Swedish Deaf, for instance, is one of the official second languages of Sweden, and users of Swedish Sign Language, as a result, have all the language rights accorded to users of an official second language. Deaf people thus have a legal right to receive their schooling in signed language, and to have sign language interpreters provided for all their official interactions with the hearing public. This provides them with full access to the life of the country.

Some natural signed languages, such as American Sign Language and British Sign Language have been fostered and developed, and as a result, their oral tradition has spawned a body of signed language literature, which is now captured on videotape and is studied and analysed. Thus, just as users of other languages keep a more permanent record of their artistic creations by writing them down and studying them, users of signed languages, with the help of videotechnology, have taken the opportunity to do the same.

These are a few examples of signed languages in countries which have recognised the language rights of their citizens and made provision for the development of these languages. More common, world over, is a deep and unfounded prejudice against 
signed languages, and a consequent marginalization of Deaf people and their human rights.

\section{Signed language in South Africa}

It is estimated that approximately 500000 South Africans use a signed language in their daily lives. The vast majority of these are Deaf, although there is a small number of hearing people, usually children of Deaf adults or professionals working closely with members of the Deaf community, who use signed language regularly and frequently.

Although South African Sign Language is not one of the eleven official languages of South Africa, it is mentioned explicitly in the Constitution of the Republic of South Africa as one of the languages of South Africa that must be promoted, and for which adequate conditions for ongoing development and use must be created. Furthermore, and importantly, the South African Schools Act of 1996 states that South African Sign Language is to be the medium of instruction (now known as the language of learning) in schools for the Deaf. Thus, although South African Sign Language is not an official language of the country, it does have the status of a medium of instruction in schools that are set up specifically to cater for the needs of Deaf pupils.

In reality, the present situation in schools for the Deaf does not, by any means, conform to the stipulations of the South African Schools Act. Deaf pupils are not educated through the medium of a signed language, either because there are very few teachers of the Deaf who are fluent in a signed language, or because the schools have policies that allow for a combination of speech and signs (an awkward and unnatural pastiche), or the schools have policies of total oralism. Aside from the fact that the current situation is illegal, and violates the human rights of Deaf pupils, who do not physically have access to a spoken language, owing to the obvious fact that they are unable to hear, there are serious linguistic issues at stake that have ramifications for the education and literacy of Deaf children and for their future as productive citizens of the country. 


\section{Historical development of South African Sign Language}

\section{Schools for the Deaf}

The history of the signed language used in South Africa is closely linked to the development of schools for the Deaf. As is the case world-wide, in South Africa, signed language developed where there were communities of Deaf people who used their hands and faces in order to communicate. The most natural places for this to have happened are residential schools for the Deaf, irrespective of their official policies on signing. Deaf people tend to seek out communities of other Deaf people, and the signing that has evolved around school centres tends to spread into Deaf communities, even if only some of their members have actually attended school.

Not only did residential schools for the Deaf provide the physical conditions for signed language to evolve, they were and are the centres for the evolution of Deaf culture. It is in schools for the Deaf that the pupils understand that what they have in common is the fact that they are all Deaf, and that, in general, their families are not, and that they can communicate naturally and easily with other Deaf people. They realise their difference from the hearing world because of the way in which they live: without sound, needing light and face-to-face communication, using other ways to call and contact one another. In the past they have also had to hide the most binding and precious unifying practice: their use of signed language.

On another level, Deaf pupils start to understand that there are bonds that unite them to other Deaf people as a sort of extended family. Many Deaf people continue to live and socialise with other Deaf people, as adults. They regard other Deaf people as their primary community, with whom they share a common language, way of living, and sets of experiences, which bond them to one another. Thus, many Deaf people regard their primary culture and community as revolving around the use of signed language and the experience of Deafness. In most cases, Deaf people are not born into this culture: they choose it, usually as a result of negative communication experiences in their own families and with the hearing world, and the sense of 
familiarity and belonging they feel in interaction with other Deaf people. Typically, Deaf South Africans choose the company of other Deaf South Africans, and believe they are united on the basis of language and culture.

Little is known about the history of the Deaf in South Africa, prior to colonisation (Heap, to appear). After colonisation, and the beginning of publically provided education, the state authorities took little or no responsibility for establishing schools for the Deaf, and this was left almost entirely to the different churches. During the course of the twentieth century, once schools had been established and were functioning, they were eligible for some state aid. It was not until the new Constitution of the Republic of South Africa in 1996 that education was declared compulsory for deaf children. It should be noted that in South Africa (before 1994) the majority of Deaf children had never been to school.

The history of sign language in South Africa is, of course, deeply intertwined with the history of apartheid schooling and its complicated language policies. For this reason, we present some of the details of the history of Schools for the Deaf in South Africa, with particular reference to the role of different churches, and apartheid racial and ethnic classifications. Additionally we highlight the different communication practices that emerged or were prescribed in the different schools for the Deaf.

To help the reader find a way through the morass of detail, we provide a guiding generalisation: schools for the white Deaf insisted on oralism, whereas schools for the other races allowed some measure of manualism (in most cases, not a natural signed language, but a mixture of speech and some signs). It is clear that speaking was perceived by the authorities as the prestigious form of language, hence the insistence on oralism in schools for the white Deaf, whereas, based on pigmentation, manualism was permitted increasingly in schools for the Deaf of other racial groups.

The churches most deeply involved in establishing and running schools for the Deaf in South Africa were the Dominican Catholics, and the Dutch Reformed Church. 
The first school for the Deaf in South Africa was established in Cape Town in 1863 by the Irish Dominican Order, under the leadership of Bishop Grimley ${ }^{4}$. This school, from its inception, catered for all race groups, and used signed language as a medium of instruction. The Dominican nuns, who came from Ireland, had been influenced by the policy of signed language instruction originating in France in the eighteenth century, as a result of the work of the Abbé Charles Michel de l'Epée. In. contrast, the policy in Deaf education in Britain and Germany was strictly oral, that is, Deaf children were taught to lip-read, and made to speak. In Ireland, however, probably owing to Deaf education being in the hands of the Catholic Church, the French policy of manualism was entrenched.

A landmark event in the history of Deaf education world-wide was the Conference of Milan, in 1880. All Deaf delegates were excluded from voting, and the World Congress of Educators of the Deaf voted for a policy of strict oralism in Schools for the Deaf. This effectively excluded Deaf teachers from teaching Deaf children and led, in most Deaf schools of the world, to signed language going underground. It should be noted that Deaf people, wherever they were, did not stop signing to one another. However, signed language world-wide was frowned upon as a medium of instruction, and in many cases, was forbidden. The use of signed language also became stigmatised, and Deaf people, particularly those who wanted to consider themselves educated, did not sign in public.

By the time of the 1904 census, however, the Dominican Grimley Institute in Cape Town (also known as St. Mary's) still embraced a policy of manualism in the school. At that time two other schools for the Deaf had been established in South Africa. These schools served only white deaf children. The Worcester School for the Deaf and Blind was established in 1881 , by the Dutch Reformed Church, for the children of the Dutch settlers. The 1904 census report states that combined oral and manual methods were used in the school. The folklore is that Jan de la Bat, a Dutch Reformed Church missionary, taught his Deaf brother by means of signs, and that this heralded the beginning of the stgned language used in Worcester, which is

\footnotetext{
${ }^{4}$ Note that this was before South Africa existed as a single national state, some 47 years before Union. Stellenbosch Papers in Linguistics, Vol. 31, 1998, 1-28 
claimed by this community to be indigenous. Only "European" children were permitted to attend this school.

In 1884, German Dominican nuns established a school at Kingwilliamstown in the Eastern Cape. This too was a school for the "European Deaf" and followed a policy of strict oralism, presumably because of the overwhelming influence of oralism in Germany. The German Dominican School later moved to Johannesburg, where it became St. Vincent's School for the Deaf, which took in only white Deaf children.

In 1933, the Dutch Reformed Church set up another school, for the "Coloured" Deaf, known as Nuwe Hoop. The language policy was the same as that at the Worcester school for the white Deaf: spoken Afrikaans, and some manualism.

The Grimley Institute for the Deaf in Cape Town remained racially integrated, and in the 1920s segregated the children on the basis of whether they were to use manualism or oralism. This occurred after one of the sisters visited the German Dominican School in Kingwilliamstown, and instituted a policy that all but the most "backward" children would be taught using the oral method. In 1937, the Irish Dominicans opened a separate school for the "non-European" Deaf in Cape Town at Wittebome. Both "Coloured" and African Deaf children were admitted to the school. However by 1953, once the Nationalist government refined the policy of apartheid even further, the Dominican Grimley School at Wittebome was declared a school for Coloured Deaf only'.

In the 1960s, the white Dominican Grimley School for the Deaf moved to Hout Bay and adopted a policy of strict oralism which it has continued to this day. Pupils are expected to maintain strict separation from any signers, and absolutely no signing is permitted on school premises.

In 1962, owing apparently to the fact that there were still African students trying to attend the Wittebome school, a separate school for African Deaf children was set up

\footnotetext{
${ }^{5}$ We use apartheid terminology in order to show the distinctions that were maintained.
} 
in Hammanskraal (then in the Transvaal Province, some $1600 \mathrm{~km}$ away from Wittebome), also by Irish Dominican nuns, from the Wittebome School. Note that there was no school for the African Deaf in the Western Cape and no attempt to set one up until 1986. This was in accord with the Nationalist Government's policy of influx control (in terms of which no African children actually officially belonged in the Westem Cape). Only after influx control had been officially scrapped in 1986, did the Dutch Reformed Church set up a school for the African Deaf in Khayelitsha, Cape Town.

The first school for black Deaf children, Khutlwanong, was opened in 1941, near Roodepoort in the Transvaal. Started originally by the Johannesburg Deaf and Dumb Society, it was taken over by Dutch Reformed Church trustees in 1954. At this school, a system of signs, invented in Britain, known as the Paget-Gorman system, was introduced, and teachers and pupils were to speak and simultaneously use the Paget-Gorman signs. This was a policy that was to spread to other schools for black Deaf pupils. The Paget-Gorman system was not a language but a set of invented signs, based on unnatural handshape permutations, lacking a grammar at any level.

As a result of the homelands policy, ${ }^{6}$ a number of additional schools for the African Deaf were established in the rest of the country, divided according to the spoken language of each ethnic group, and in line with the Bantustan separate development policy. Thus, from the mid 1950s, the following schools for the African Deaf were established: The Khutlwanong School moved to Rustenberg and served the so-called Tswana, South Sotho, and North Sotho "speakers"; in 1959, the Efata School in the Transkei was established for Xhosa "speakers", also under the auspices of the Dutch Reformed Church; in 1962, the Dutch Reformed Church set up Bartimea School at Thaba'nchu for Tswana and South Sotho "speakers", and in 1965 the Vuleka school

\footnotetext{
${ }^{6}$ This was the apartheid policy of separate devclopment, in which the idea was to separate white South Africa from black South Africa, and then further divide black South Africans into a number of ethnic groups, each with its own "homeland". Black people were then considered "citizens" of their designated homeland, and not South Africans.
} 
at Nkandla for Zulu "speakers". The Catholic Church established St. Thomas at Stutterheim for Xhosa "speakers", in 1962. The Tsilidzini school at Shayadima, was established to serve Venda and Tsonga "speakers"; the Thiboloha School at Witsieshoek, served South Sotho "speakers. The school set up in 1962 by the Dominicans at Hammanskraal officially catered for Sotho "speakers". In 1978 and 1981, two day schools were set up for urban black Deaf children, one in Soweto and one in Katlehong.

Until the 1980s the official medium of instruction in all these schools was mother tongue, although in the case of Deaf children, it was not clear what this was. Additionally, the schools were instructed to integrate the Paget-Gorman signing system with mother tongue speech. As was the case generally with education for black people in South Africa in these years, the whole idea of dividing schools up on the basis of the mother tongue of their pupils was fraught, and based on partial, and often incorrect information. In the case of the Deaf children, this was even more confused. Further, the use of rudimentary signs to accompany the spoken language made the official language practices even less communicatively accessible to the Deaf children. Later, English or Afrikaans was brought in as the official medium of instruction in schools for the black Deaf, with the added feature of the Paget-Gorman signs. With this change, the logic of ethnic separation on the basis of home language was rendered even more ridiculous. In practice, in schools for black Deaf children, the teachers used an ad hoc system of sign supported speech (it is unclear whether they used English, Afrikaans, or a Bantu language). This practice is known in Deaf education as "total communication" but has, in fact, almost no communicative effect at all. On the ground, in these residential schools for the Deaf, the pupils, left largely to their own devices, developed their own signed language.

It is known that in the schools for the black Deaf, there was little access to hearing aids and speech therapists. Although there was an official oralist policy, sign language thrived. Most of the schools for the African Deaf were vastly underresourced, under-funded, and understaffed. In these schools children were not forbidden to sign, and a very small number of the teachers picked up some sign language from the children. Less school time was wasted teaching children to speak, 
and although these Deaf children received an atrocious general education, an unexpected benefit of the neglect was the development of strong centres of natural signed language use.

As far as the other racial groups were concerned, in the 1950s schools for white Deaf children from Afrikaans homes were set up in Pretoria (the Trans-Oranje school) and the Free State. These schools were offshoots of the De la Bat school in Worcester, and all under the auspices of the Dutch Reformed Church. The Fulton School for children from English speaking homes was set up in Natal by the Anglican Church in 1958. An "Indian" teacher was trained by the nuns at Wittebome, in order to set up the VN Naik school in Natal for the "Indian" Deaf, and later the MC Karbai school for the "Indian" Deaf was started in Lenasia. The policy in all these schools was oralist, with signing discouraged, and not used in the classroom.

\section{The spread of signed language}

Despite the official language policies, in all the residential schools for the Deaf in South Africa, pupils signed with one another, and signed language flourished, out of the classroom. If the pupils of all these schools were to have stayed in the geographical location of the school, and not returned home, or moved around the country, it would be reasonable to expect that each of these centres produced its own sign language and that these stabilised. It is a very plausible hypothesis that as a result of apartheid education and social policies, different signed languages developed in South Africa. This hypothesis was most clearly articulated and accepted by the makers of the Dictionary of Southern African Signs (Penn et al 1992a). However, there are a number of facts that cast doubt on the veracity of this hypothesis.

Deaf people moved around the country. As a result of the apartheid system of schooling, Deaf children often had to leave the geographical area of their homes to go to school. After leaving school, they either returned home or went to work and live in other parts of the country. Deaf people also socialise with other Deaf people. More recently, there has been signing on television in programmes for the Deaf, and 
interpreting of national news, and thus, Deaf people are exposed to the signing of different sectors of the Deaf community. There are frequent local and national Deaf events of a sporting, cultural, and educational nature. Initiatives have been launched for the Deaf people within provinces to hold regular forums; in the last few years, national Deaf "indabas" have been held. Deaf people are beginning to train other Deaf people to teach sign language irrespective of whether or not they are from the same community. Anecdotally, the most convincing piece of evidence is that Deaf South Africans seem perfectly able to communicate easily with one another, although it is revealing that many Deaf people believe that there are different sign language varieties in South Africa.

There seem to be reasons to claim that if there are different varieties they are converging $^{7}$, as is the case in South Africa with different Englishes ${ }^{8}$. There is also a strong possibility that natural harmonisation is taking place, owing to the far greater mixing of different communities with one another, and the (very minuscule) integration of Deaf schools.

The linguistic decision as to whether there is one South African Sign Language or whether there are many can only be made on the basis of linguistic research. To this end there is a project underway to investigate the structural properties of the signed language used by different communities in South Africa ${ }^{9}$. However, the decision is also a social one, as people's perception of whether they use the same language as other people, or a different one, is frequently based on considerations other than the structural properties of the language. In the remainder of this article we examine these other considerations, some of which are pertinent to languages in general, and some of which have particular bearing on South African Sign Language.

\footnotetext{
${ }^{7}$ For a discussion of convergence, see Thomason and Kaufmann 1988, and for a discussion of the convergence of signed language varieties see Akach and Okombo 1997.

${ }^{8}$ See e.g., Lanham 1996.

${ }^{9}$ An investigation into the linguistic structure of the signed language/s used in South Africa. CSD
} Stellenbosch Parant number 15/1/3/16/0125 to Debra Aargns and Ruth Morgan. 


\section{How many signed languages are there in South Africa?}

The question that seems to beset the official development of South African Sign Language in South Africa is one that might appear to be a non-question: How many different signed languages are there in South Africa? There are many different ways of going about answering this question, the first of which is to ask why it is being asked. Generally, the official response has been that until we know the answer to this question we cannot choose a standard variety, and only then can we begin with interpreter training, and sign language training for pre- and in-service teachers, and with the introduction of television interpreting, school curricula and syllabi for South African Sign Language, and so on. The next question we might ask is: Who is asking? And we may find that it is not Deaf people who are asking this question, but educators of the Deaf, would-be interpreters, bureaucrats, and financial managers. For it is costly in terms of time, effort and money to have to take responsibility for the promotion and development of yet another language group in South Africa.

We propose to examine a number of the claims that underlie the commonly heard statement that there is more than one sign language in South Africa. Not all the claims are compatible with one another, as they are merely culled from received wisdom, and set down here as a list. We show that in all these cases, the factors that are brought to bear on the discussion of the signed language are non-linguistic ones. They have nothing to do with the structure of the language itself. We will list these below as baldly as possible in order to explicate them:

\section{Claims}

1. For every different spoken language in South Africa, there is an equivalent signed language, i.e., there is an English Sign Language, an Afrikaans Sign Language, a Sotho Sign Language, a Zulu Sign Language, etc.

2. For every different racial and ethnic community in South Africa, there is a different sign language. Thus, for example, ethnically Indian South Africans have their own signed language, English-speaking Coloured South Africans have their Stellenbosch Papers in Linguistics, Vol. 31, 1998, 1-28 
own signed language, Afrikaans-speaking Coloured South African have their own signed language, and these are different from the white English or Afrikaans South African signed languages.

3. For every different geographical or ethnically separated Deaf community there is a different signed language. Thus, Deaf people from an English school in Natal use a different signed language from that used by Deaf people from an English school in Johannesburg.

4. There is a word for every sign and a sign for every word (for argument's sake, in English).

5. Signed languages mirror the morphological and syntactic structure of the spoken languages from which they derive.

6. Signs or signed language utterances do not vary in their context of use.

7. A standard language does not allow for regional, ethnic, gender, situational or contextual variation.

8. If people are born into a certain community, or culture, their primary loyalty and identification must be to the language used in that particular community.

In order to make our case quite clear we will make some counter-claims about South African Sign Language and then substantiate them. We claim firstly that the reason that some people say that there are different signed languages in South Africa is based on a fundamental misunderstanding of the signed language itself, i.e., they assume that signed language is a manual version of spoken language (claims 1, 2, 3). Secondly, we claim that the Dictionary of Southern African Signs is based on a false hypothesis about the effects of apartheid on the signed language used in South Africa, as well as a simplistic understanding of the relationship between words and signs, and a failure to recognise variation within different contexts of use (claims 4, $5,6)$ and although there are certainly different varieties of the signed language used 
in South Africa, most Deaf people in the country control many of these varieties, as is the case for speakers of any other language (claim 7). Thirdly, we claim that Deaf people themselves frequently confuse language identity with other kinds of identity and thus sometimes reject the signing of other Deaf people as "other" (claim 8).

\section{Claims that are challenged}

(a) A signed language is a manual version of a spoken language (claims 1, 2, 3)

Languages have their own word order rules. Thus the word order of English is different from that of Afrikaans, which in tum is different from Japanese. If we were to arrange English words in Japanese word order we would no longer be speaking English. Nor would we be speaking Japanese. Similarly, to take one sign for every English word and arrange these signs in the word order of an English sentence is not to produce an utterance in a natural signed language. Nor is it English. It is an attempt to put English on the hands and it is doomed to failure, for the following reasons.

Signed languages have their own way of realising their grammatical structure. They are not based on any spoken language. They exploit the medium of space efficiently, using location and movement, two of the properties of space, to encode features such as inflection, verb agreement, deixis, and aspect. Further, the grammar of signed languages is made through facial expressions and head positions. The essential syntactic organisation of signed languages is no different to the syntactic organisation of any other human language that has been analysed in these terms, but the surface realisations are those that befit a visual medium, rather than an oral one.

Various attempts have been made to put spoken languages on the hands. The basic idea is to match each word and morpheme in a spoken language with a signed analogue: These codes are clumsy, partial, and inefficient. They are based entirely on the misapprehension that the only way in which languages differ is in the words they use. An equivalent mistake would be to translate English morpheme by morpheme into Zulu morphemes, without changing the morpheme order or the word order, and, 
in the case where there is no equivalent morpheme, to invent one. Similarly, Manual Coded English (MCE) is an attempt to put the surface morphemes of English onto the hands, in an attempt to teach Deaf people English. However, signed languages do not have signs for "the" or "-ed" or "-ing", because the features of definiteness, tense, and aspect are realised differently in signed languages. So, the designers of these codes invented signs for these and other morphemes. Such invented signs do not participate in the spatial grammar of a signed language, which uses a change in the movement of the sign itself, or a facial expression, to express different sorts of inflections.

The results of these inventions are clumsy, inefficient codes that are unable to be processed, or acquired. They are not natural sign languages, and they are not even good representations of the spoken language, since they code only the surface morphemes of the language. Furthermore, they do not lead to literacy in the spoken language that they attempt to model. Deaf people do not use them when they communicate with other Deaf people. However, these codes are much favoured by hearing people who want to communicate with the Deaf. Essentially they take the words and word order of a spoken language and try to fit signs into this framework. This is invariably accompanied by speech. It is the use of these artificial codes that gives rise to the idea that there is an English Sign Language and an Afrikaans Sign Language, a Sotho Sign Language and so on.

The main problem with this idea is that no-one uses these codes naturally. Deaf people when communicating with one another use natural signed language, and are not cut off from other Deaf people in their area because they are users of "Sotho" and not "Afrikaans". It should also be noted that the only people who are able to use these codes are those who already know the spoken language itself: the codes are no aid to language acquisition. The idea that there are many different signed languages in South Africa is one that has been manufactured by hearing people who have decided on the easiest way for them to "communicate" with Deaf people, without actually learning the language of the Deaf themselves. 
The notion that there is a different signed language for every ethnic and racially different Deaf community in South Africa is a very confused one. At first glance it is contradictory to the idea that there is a signed equivalent to every spoken language. However, it is indeed the logical extension of the apartheid idea: different communities have different languages. It is further complicated by the claim that Coloured communities have different signed languages depending on whether they are "English" or "Afrikaans" speaking. This assumes that Coloured Deaf communities are divided along the lines of whether they use English or Afrikaans, and takes us back to the problems stated above. It also assumes that "Coloured English Sign" is different from "Coloured Afrikaans Sign", which is in turn different from "White Afrikaans Sign". This confusion has all the hallmarks of an apartheid design writ large.

As it happens, given the relationship of the schools to one another, for instance, the fact that the Irish Dominican teachers controlled white, Coloured, Indian and black Deaf schools, these varieties usually have a good deal in common. Further, the fact that some Coloured students might have attended the Dominican school in Cape Town, and others the Nuwe Hoop school in the Cape, does not mean that they did not go home to similar communities. There are very few people who would be prepared nowadays to defend, in its purest form, the claim that there is a different signed language for every ethnic and racially different Deaf community in South Africa.

The claim about ethnically and regionally divided communities using different sign languages is a similar one. If Deaf people from white English schools in KwaZuluNatal use a different language from the one used at a white English school in Johannesburg, then this too contradicts the idea that there is such a thing as an English Sign Language. As it happens, there seems to be no communication problem between people from these two schools. We have shown above that it is unlikely that the natural signed language is based on English. Thus, there must be other reasons for the mutual intelligibility. It is possible that the influences on the signed language are similar; it is very likely that members of these Deaf communities mix outside of school. Nowadays, it is not even entertained by Deaf people that the language used 
by (white) Deaf in Johannesburg and Durban is significantly different. Thus, we know (at least for these communities) that despite different geographical regions, and the fact that the Deaf people do not use signed English, there is a common signed language. We also know that white Deaf people from De la Bat in the Cape (a socalled Afrikaans school) communicate very well with white Deaf people from St. Vincent's in Johannesburg (a so-called English school). Some claims have been made that in the white schools for the Deaf, the students learn English and Afrikaans, and that they use signed forms of the spoken language to communicate. A cursory glance at the written English or Afrikaans of Deaf school leavers in South Africa should give the lie to the fact that the average Deaf pupil has enough literacy in a second or third language to even begin to try to put it on his hands.

We are thus left with the idea that colour may be the variable, and this is certainly what some Deaf people believe, although it is very difficult to propose a logical account for why this should be so. Indeed, if we recall the history of the language medium policy in black schools for the Deaf, we see that until the 1980 s every school was meant to use the spoken language of the pupils' homes, plus some PagetGorman signs. During the 1980s, officially English and Afrikaans would have been used, along with Paget-Gorman. None of this explains why Deaf black South Africans from ten different mother tongue backgrounds communicate easily with one another in signed language, nor why there are conflicting reports from Deaf South Africans of different racial groups about whether or not they use the same signed language.

What we do know is that Deaf people seem to manage very well to communicate with one another across racial boundaries, until there are hearing people (teachers, social workers, "interpreters") involved. Apparently, many hearing people use manual codes that are associated with a particular spoken language. Then only the Deaf people who understand the particular spoken language understand them. Similarly, some hearing people may understand a signed form of a particular spoken language, but not the natural signed language used by the Deaf themselves. Invariably, it is the hearing people who raise the complaint that they do not Stellenbosch Paperstand "Zulu sign language" in Lingüstics, "Afrikaans sign language". 
Combined with the complication of accommodating to hearing people's signing, is the issue of colour. South Africans notice. It is our observation that signers tend to decide whether someone else's sign language is the same as theirs or different, on the basis of their skin colour. A skilled signed language interpreter in the Western Cape (totally bilingual in English and Afrikaans as well) who happens to be a "Coloured" South Äfrican was informed that the white Afrikaans Deaf did not understand him. Conversely, one of the authors, who happens to be Kenyan, and knows no local Bantu languages, is frequently complimented by Black South African Deaf people on how well he uses the local signed language.

(b) As a consequence of apartheid, there are many different signed languages used in South Africa (claims 4, 5, 6, 7).

In 1980, a limited collection of signs, apparently in use in schools for the black Deaf (many of them unnatural, some based on the Paget-Gorman system) was produced, under the auspices of the Department of Education and Training (the department responsible for the education of black people at that time) by Norman NiederHeitmann, the principal of the Khutlwanong School. The book was called Praat met die Dowes (Talking to the Deaf). Subsequently, this book was prescribed for use in schools for the black Deaf and constituted the only permissible signs that could be used.

In the mid-1980s, the Human Sciences Research Council (HSRC), the state-funded council for scientific research, advertised for a researcher to work on the standardisation of South African Sign Language. The Dictionary of Southern African Signs (Penn et al 1992) was the final outcome of the work commissioned by that research council. It was developed over seven years at considerable cost, and consists of five volumes.

Clearly, as shown above, the various Deaf communities did not mix much over the years preceding the dictionary, and as one would expect, the signed language used by different groups would have shown some lexical variation, a variation perpetuated by 
apartheid divisions. The Dictionary focused on these lexical differences, attempting to correlate the different lexical items with the spoken language communities into which the Deaf users were born. To this end, the project team documented signs from eleven different racially and regionally based areas in South Africa. Researchers used English words and phrases to elicit particular signs from the representatives of each community. These signs were videorecorded, and then a still frame was made from each, and presented as the sign used by the different communities for the particular English word or phrase. Thus, each page of the dictionary listed an English item, then showed eleven or so different signs that informants claimed were the ways in which the sign for this English word was used in their language variety.

It is difficult to see what purpose the dictionary would have in standardising the signed language used in South Africa into a single signed language. It seems more likely that the dictionary could have been used to standardise each of the different varieties. This idea is quite in accord with the practice under apartheid, whereby Language Boards for each Bantu language were set up, usually comprising nonnative speakers of that language. The standard for that language, for instance Xhosa, was then decided upon, and then this standard variety was prescribed for use in and teaching in schools. Native speakers of the language, e.g., Xhosa, found that their own variety was then deemed to be faulty as a consequence of the decrees of the Language Board ${ }^{10}$.

It should also be noted that the dictionary had a stated pedagogical aim (Penn 1992a; Penn and Reagan 1994). Thus, its purpose was not only to describe the varieties used by the different communities, but to use the items for teaching one or other signed language. The issue of signed language syntax is not addressed directly in the dictionary itself (although there is some discussion of the syntax of signed languages in general, in the introduction to the Dictionary). The pedagogical aim, then, seems geared more to teaching some sign vocabulary within the context of an English sentence structure. The pedagogical outcome of such an approach is unlikely to be the acquisition of a natural sign language.

${ }^{10}$ See e.g., Nyamende 1994.

Stellenbosch Papers in Linguistics, Vol. 31, 1998, 1-28 
The first serious misunderstanding upon which the Dictionary of Southern African Signs is based, then, is that the structure of a signed language is dependent on the structure of a related spoken language. The second misunderstanding is that there is a one-to-one relationship between a lexical item in one language and a lexical item in another, i.e., that there is a simple word-sign relationship. In any event, the base items for elicitation in the dictionary were English sentences. It is not clear what the dictionary makers see as the relationship among the different spoken languages in South Africa, the relationship of these to the signed varieties, nor the relationship of signed items in an utterance to one another.

Signed languages are essentially based on a complex system of classifier handshapes of movement and location. These form the skeletal structure for most predicates involving movement or location. They may translate as a long string of words, such as, "a car goes very fast up a steep hill with hairpin bends". Each of these separate pieces of information is embedded as a morpheme into one sign, that uses its handshape, movement and location to convey all of this information. The purpose of this example is to show (i) that there is no simple word-sign equivalent; (ii) making a dictionary of signs also requires an understanding of the morphological and syntactic structure of a signed language; (iii) arranging a dictionary according to the spoken language makes it virtually impossible to look up the meaning of a sign, but only makes it possible to look up a signed equivalent for a word. Thus, the dictionary seems to be designed for the use of hearing people who want to communicate in a rudimentary way with Deaf people (assuming, of course, that they know the "variety" that the Deaf person uses).

We have already mentioned that the word order in signed languages may be different from that in spoken languages. Thus, no user of the dictionary would be able to construct the simple sign language utterance/s that might be translated as "The girl kicks the boy".

The possible sign orders are, at least, the following: 
GIRL (point over here) BOY (point over here) KICK

GIRL (topic facial expression) KICK BOY

BOY (topic facial expression) GIRL KICK

There are other permutations, depending on aspects of the discourse context.

As we have argued above, as well, morphological affixes in English, or any other spoken language, do not have one-to-one equivalents in signed languages. In general, the morphology of signed languages is agglutinating, as well as simultaneous. Thus, as shown above in the example, "a car goes fast up a very steep hill with hairpin bends", all these morphemes occur simultaneously in one sign. Signed languages uses differences in the internal movement of the base sign itself to show morphological inflection. Thus, "look for a long time"; "look intently"; "look now and again"; may each be represented by one sign. These signs have the same handshape, but differ from one another on the basis of the internal movement of the sign. Affixes like the English "-ing" find their equivalent in verb movements that express continuousness, or other temporal aspects. None of this information is to be found in the Dictionary.

However, a close examination of some of the signs listed in the Dictionary as translations into different varieties for the same English word, reveals that some of these signs differ only in some or other inflectional aspect, and should not be considered as different signs, but as different inflections of the same sign.

Additionally, the Dictionary does not take into account that there is more than one possible sign for a given lexical item, so that although an informant might provide one sign, this does not mean that $\mathrm{s} / \mathrm{he}$ does not know or use others on different occasions or in different contexts. The way that the dictionary is presented leads to the false impression that there is only one sign that is suitable, even given a restricted context of use. 
It is also the case that signed languages, just like other languages, have different registers, for formal and less formal occasions, that there are polite and less polite signs, that there is slang, fast signing, in-group signing, and all the other variations that other languages boast, depending on the context of their use. The elicitation and presentation of items for the Dictionary does not take these factors into account at all.

Penn and Reagan report that during the elicitation and decision stages of the Dictionary, some of which happened in committee with all the other informants, representatives insisted that their particular sign for an item was the correct one (Penn and Reagan 1994). The Dictionary, being a creature of its time, seemed to evoke Deaf informants' sense of their ethnic, rather than Deaf identity. However, later, as changes started to happen in South Africa, and Deaf people began to mix across racial and geographical boundaries, many Deaf people noted that their signs were mutually intelligible.

Interestingly, as well, on completion of the Dictionary, a number of the Deaf informants commented that they understood the entire range of signs, irrespective of the ones which they themselves would have used in the particular context of elicitation.

Not enough research has actually been conducted on the signed language used in South Africa, to make the claim one way or the other. The authors of the Dictionary claim that there is a syntactic unity in the different signed languages they examine, but their claim is based on research using only one sector of the signing community, and this claim, is in any event, geared to showing that there are syntactic universals in signed language, based on the grammatical use of space (Ogilvy-Foreman et al 1994; Penn and Reagan 1994). This claim is so general that it does not tell us anything at all about the structure of signed language in South Africa, other than that it is a subset of the natural signed languages of the world. Aarons and Morgan (forthcoming) are investigating variation in different sign language communities at the phonological, morphological and syntactic levels, bearing in mind that the greatest source of variation within a single language is its lexicon. They believe that if 
they can show that there is uniformity at the phonological, morphological and syntactic levels, they are entitled to claim that there is a single signed language in use in South Africa today ". Furthermore, this process of investigation is designed to involve Deaf people being trained to do linguistic research at all levels, so that the research can feed back into the Deaf community and be of some use to that community in empowering Deaf people to be the experts on their own language ${ }^{12}$.

Thus, although we do have a large and official set of documents that declare there are many different signed languages in South Africa, and despite the fact that this was a reasonable hypothesis given the separation wrought by apartheid, we see that it turns out to be based on some faulty understandings about the nature of signed languages, the role of dictionaries, and the part played by other historical forces in the education and socialisation of Deaf people.

Finally, languages develop and change very fast, particularly when they are not written down. There is much more movement and fluidity in the Deaf community than there used to be, and Deaf people from all sectors mix more with one another, watch others signing on television, engage in Deaf sports and education meetings, and are much more aware that the method of communication they use is a language worthy of respect and study. Along with this natural convergence, another force is coming into play. Deaf people have started to take pride in their signed language, and are wearing it as a badge of their identity.

(c) Deaf people's primary loyalty is to the community, or culture, into which they were born. They must identify with the culture, and hence the language used in that particular community (claim 8).

This is a complex issue. Deaf South Africans are also South Africans, and suffer from all the complicated identity issues with which other South Africans struggle. Thus,

\footnotetext{
"To establish this uniformity, in conjunction with the well-documented ubiquitous process by which classifier morphemes are used in signed languages of the world, would seem to be sufficient to make the claim that the same language is being investigated, irrespective of lexical variation.

${ }^{12}$ See Aarons 1994; 1996.
} 
they also have to sort out the issues of race, ethnicity, culture and language. Most Deaf people use a different language from their parents (except those who were born to Deaf parents). Deaf people in other countries who are Deaf-identified believe they have a separate Deaf culture lodged within the mainstream hearing culture of the society. They say that they have a separate language, and a different way of doing things and living their lives, and therefore their culture is different from that of the mainstream hearing culture, although it is lodged within the mainstream culture of the country.

Many Deaf South Africans are beginning to say that they are first Deaf, and then they list their other identifications. Invariably the next two are colour and home culture. In our observations (although this is yet to be established formally), the majority of black Deaf South Africans say that they are first Deaf and then black. The most striking claim is from white South Africans of Afrikaans origin. Many of these people say that they are first Deaf and then Afrikaans, or even, first Afrikaans and then Deaf.

It is interesting that when questioned, people in the above group see being Afrikaans as being their strongest cultural affiliation. This has several consequences: it lends a great deal of emotional support to the claim that there is a separate Afrikaans signed language and it provides these Deaf people with further and closer identification with their home mainstream culture. Thus, despite acknowledging, when pushed, that signed language is not Afrikaans, they say that they are Afrikaans. This is a cultural identification, not a linguistic one. It appears to be strongest among white Afrikaans Deaf people.

Amongst the other Deaf people in South Africa, race is usually second on the list of identities. Black Deaf people see themselves as different from white Deaf people, and vice versa. It often happens in meetings that these different communities say they can't understand one another's signed language, and then it is common for people to refer to one another's languages as "black signed language" or "white signed language". When the language samples are analysed, the analyst may be forced to the conclusion that the failure of comprehension is not related to the language use itself, but to the ways in which the users perceive one another. It is not difficult to account Stellenbosch Papers in Linguistics, Vol. 31, 1998, 1-28 
for why this should be so, but it would be a mistake to attribute the problems in understanding to differences in the signed language.

\section{Conclusion --the linguistic human rights of Deaf people}

As Deaf people in South Africa become more committed to Deaf rights, Deaf consciousness, Deaf pride, Deaf unity and Deaf power, these language differences seem to become smaller. Deaf people start to see themselves as bound by a common language and a common struggle. The debate about how many signed languages there are in the country becomes a non-question. This divisiveness serves the needs of communities other than the Deaf and must be recognised as arising out of important social forces that have bearing on the social and political, but not the linguistic, status of the natural language of the Deaf people in South Africa. The real issue is how the rights of Deaf people as a linguistic minority can be achieved, including the right to have signed language as a medium of instruction in schools for the Deaf;, state funding for the training of skilled signed language interpreters and sign language teacher trainers, and the provision of interpreters and services to ensure equal access for Deaf people to the life of the community. 


\section{References}

Aarons, D. 1994. Aspects of the Syntax of American Sign Language. Unpublished $\mathrm{PhD}$ dissertation. Boston University, Massachusetts.

Aarons, D. 1996. Signed Languages and Professional Responsibility. In Stellenbosch Papers in Linguistics, 30. University of Stellenbosch, South Africa.

Akach, P., and O. Okombo. 1997. Language Convergence and Wave Phenomena in the growth of a National Sign Language in Kenya. In International Journal of the Sociology of Language.

Constitutional Assembly of the Republic of South Africa. 1996. Constitution of the Republic of South Africa.

De Klerk (ed.). 1996. Focus on South Africa. Amsterdam: John Benjamins.

Heap, M. (w.i.p). An anthropological perspective of the Deaf people in Cape Town. University of Stellenbosch, Department of Anthropology.

Lanham, L. W. 1996. A history of English in South Africa. In V. De Klerk (ed.) Focus on South Africa. Amsterdam: John Benjamins.

Nieder-Heitmann, N. 1980. Talking to the Deaf. South African Department of Education and Training and the South African National Council for the Deaf.

Nyamende, A. 1994. Regional variation in Xhosa. Stellenbosch Papers in Linguistics PLUS, 26. University of Stellenbosch, South Africa.

Ogilvy-Foreman, D., C. Penn, and T. Reagan. 1994. Selected syntactic features of South African Sign Language: a preliminary analysis. South African Journal of Linguistics, 12 (4). 
Padden, C. And Humphries, T. 1990. Voices from a Culture. Cambridge: Harvard University Press.

Penn, C. 1992 (a). Dictionary of Southern African Signs. Human Sciences Research Council, Pretoria.

Penn, C. 1992 (b). The Sociolinguistics of South African Sign Language. In Herbert, R.K. (ed.) Language and Society in Africa. Johannesburg: Witwatersrand University Press.

Penn, C., and T. Reagan. 1994. The properties of South African Sign Language: lexical diversity and syntactic unity. Sign Language Studies, 84.

Thomason, S., and T. Kaufmann. 1988. Language contact, creolization and genetic linguistics. Berkeley and London: University of California Press. 